\title{
Hvem var Pylorica?
}

\author{
Pylorica var kallenavnet til en kvinne som satt i luken ved inngangen til det gamle Anatomisk institutt i mange \\ tiår. Alle som studerte medisin i Oslo frem til 1961, møtte henne der.
}

Kallenavnet er intuitivt for oss medisineredet er en kvasilatinsk hunkjønnsform av pylorus, lukkemuskelen til magesekken. Vi var nesten litt redd henne. Hun passet på at vi ikke slapp inn i det aller helligste uten at vi viste adgangskortet, som skiftet farge for hvert semester.

Portnerske (concierge) er en kjent tittel, i alle fall i Frankrike, hvor enhver respektabel leiegård har en slik som man må henvende seg til for å slippe inn. Portnersker blir gjerne betraktet som litt mystiske, og det er skrevet romaner om dem, for eksempel bestselgeren Pinnsvinets eleganse (1). I den romanen hadde portnersken et hemmelig liv som beboerne ikke kjente. Det viste seg at hun var en stor litteraturkjenner. Hadde vår Pylorica et slikt hemmelig liv? Mange år etter vårt liv på Anatomen begynte jeg å lure på dette. Hvem var hun egentlig?

I tillegg til søk i elektroniske databaser (bokhylla.no, Retriever, Aftenpostens digitale arkiv, kirkebøker og folketellinger) og leting i kommunale folketellinger ved Byarkivet i Oslo og i studentbladet AEsculap for årene 1920-62 ved Nasjonalbiblioteket i Oslo har jeg intervjuet studiekamerater og daværende ansatte ved Anatomisk institutt for å forsøke å gjenfinne spor og erindringer om Pylorica.

\section{Margith Hanssen}

Jeg visste at hun het Margith Hanssen. Det ble fortalt meg av en venninne og kollega etter at Pylorica hadde vært til stede på en kullfest. Hun sa: «Var ikke Pylorica nydelig?» Hun var det. Pyntet til fest, nyfrisert og smilende, ikke slik vi så henne til hverdags. Jeg tenkte ikke mer på det den gangen.

Vi har mange arkiver i vårt land, men å lete etter navnet Margith Hanssen var temmelig håpløst. Dessuten kan navn skrives på mange forskjellige måter. Men så dukket det opp et presseklipp på hjemmesidene til Museum for universitets- og vitenskapshistorie. Det var fra Aftenposten i anledning 150-årsjubileet til Universitetet i Oslo i 1961 (2) (fig 1). Her var det et intervju med henne. Det ble fortalt at hun hadde begynt i stillingen i 1914, men nå skulle hun slutte, på sin 75-årsdag. Dermed kunne jeg ved arkivsøk rulle opp hennes liv, i alle fall rammene for det.

Margith Hanssen var født på Eidsvoll
11.11. 1886. Hun var eldste barn av Knut og Hedvig Hanssen (3). Faren var handelsbetjent, ifølge kirkeboken (3), men ved en senere folketelling står han oppført som snekkermester (4). Moren var hjemmeværende. Det er anmerket at familien ikke tilhørte noe kirkesamfunn (registrert som «uttrådt»). Margith hadde seks yngre søsken, alle født på Eidsvoll (5). Familien bodde i $1900 \mathrm{i}$ et stort hus på Fredheim, Eidsvoll (4). Den yngste søsteren var født i 1901. I folketellingen fra 1910 er familien bosatt i Kristiania, så en gang mellom 1901 og 1910 har de flyttet dit. Senere finnes Margith i folketellingene der. Faren er oppgitt å være snekkersvenn. Han må ha hatt et rimelig godt utkomme på Eidsvoll, skal man dømme etter det store huset, men jeg vet ikke noe sikkert om hvorfor de flyttet. Fra 1910 bodde hele familien på ni til leie i en treroms leilighet i Vogts gate 55 på Torshov (5).

Dette er en staselig murgård på fire etasjer, bygd i 1903. Det er dermed mulig at familien Hanssen flyttet inn da gården var ny. Dette var før den storstilte Torshovutbyggingen fra kommunens side. De bodde i øverste etasje. Gården ligger like ved den senere trikkeholdeplassen på Torshov, og Margith fikk da en fin reiserute med bytrikken til Domus Media i sentrum.

I intervjuet som er gjengitt i presseklippet fra 1961, forteller hun at hun hadde huspost hos en «professor Werner» før hun begynte på Anatomen i 1914 (2). Ved leting i folketellingene fra denne perioden har jeg imidlertid ikke funnet noen professor Werner ved Det Kongelige Frederiks Universitet. Heller ikke Museum for universitets- og vitenskapshistorie kjenner til noen professor med dette navnet (Anne Vaalund, personlig meddelelse). Kanskje det kan være feilskrift for Ole Berner (1874-1944), som fra 1908 var prosektor i histologi ved Anatomisk institutt? Ifølge intervjuet skulle vedkommende ha rådet henne til å søke stilling ved Anatomen fordi «hun kunne sy».

Ved folketellingen i 1910 hadde hun ganske riktig yrkesbetegnelsen sypike (5). Det var viktig, for ikke bare var hun portnerske, hun reparerte også alle hvite frakker som ble brukt ved instituttet. Og det var ikke få, det gjaldt selvsagt både høy og lav, inkludert studenter.

Og der var hun, i alle disse årene, til

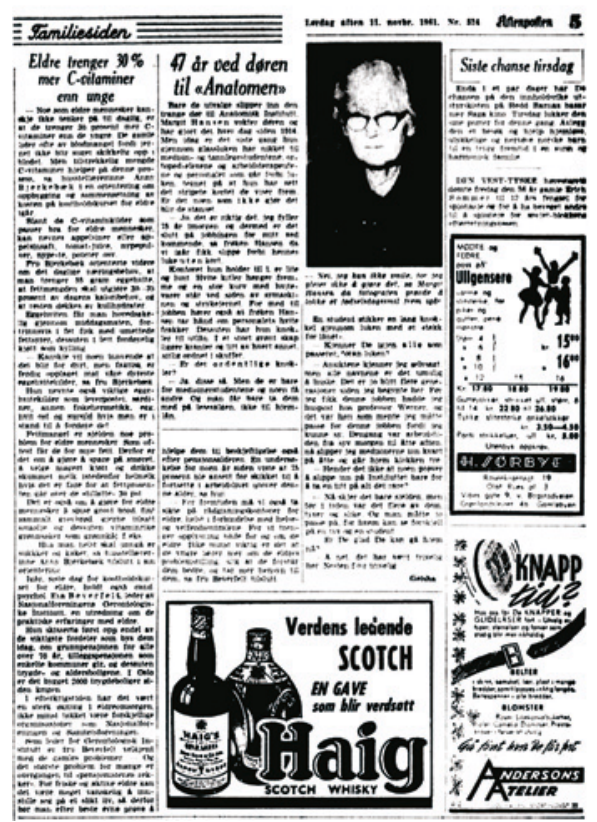

Figur 1 Presseklipp fra Aftenposten 1961 i anledning Universitetet i Oslos 150-årsjubileum (2)

å begynne med fra $\mathrm{kl} 7$ om morgenen til kl 20 om kvelden (2). Jeg har funnet en liten omtale av henne i en artikkel i bladet Alle Kvinner fra 1952 (6). Den heter Piker i hvitt, og det er intervjuer med jenter som studerte medisin på forskjellige trinn i studiet. Det er henvist til hennes symaskin og at «hun syr de nydeligste kreasjoner til levende mennesker». Jeg tror nok hun hadde selvsydd kjole på vår kullfest. Det stemmer også med en opplysning fra biografien om Nic Waal (1905-60), som studerte medisin i 1920årene. Der står det nevnt at Nic ofte hadde noe i emning hos Pylorica, sydd av gardintøy eller liknende. Nic Waal skal ha fremstått som «uhyre frigjort» og gikk med «alle de radikale studentgutta» (7).

Når Margith fikk sitt kallenavn, vet jeg ikke, men Pylorica var det vi alle titulerte henne med. Det ble også hennes etterkommere i jobben kalt. Navnet ble til og med eksportert da Det medisinske fakultet ved Universitetet i Bergen åpnet. Ved en gjennomgang av årganger av studentavisen Asculap (1920-62) fant jeg et dikt fra 1940 kalt Fra Anatomen, undertegnet «q pug». En strofe lyder slik: «D’er nok å ta av, finner man tonen i vårt liv fra Pylora til disseksjonen» (8). Det er antakelig en henvisning til Pylorica. 


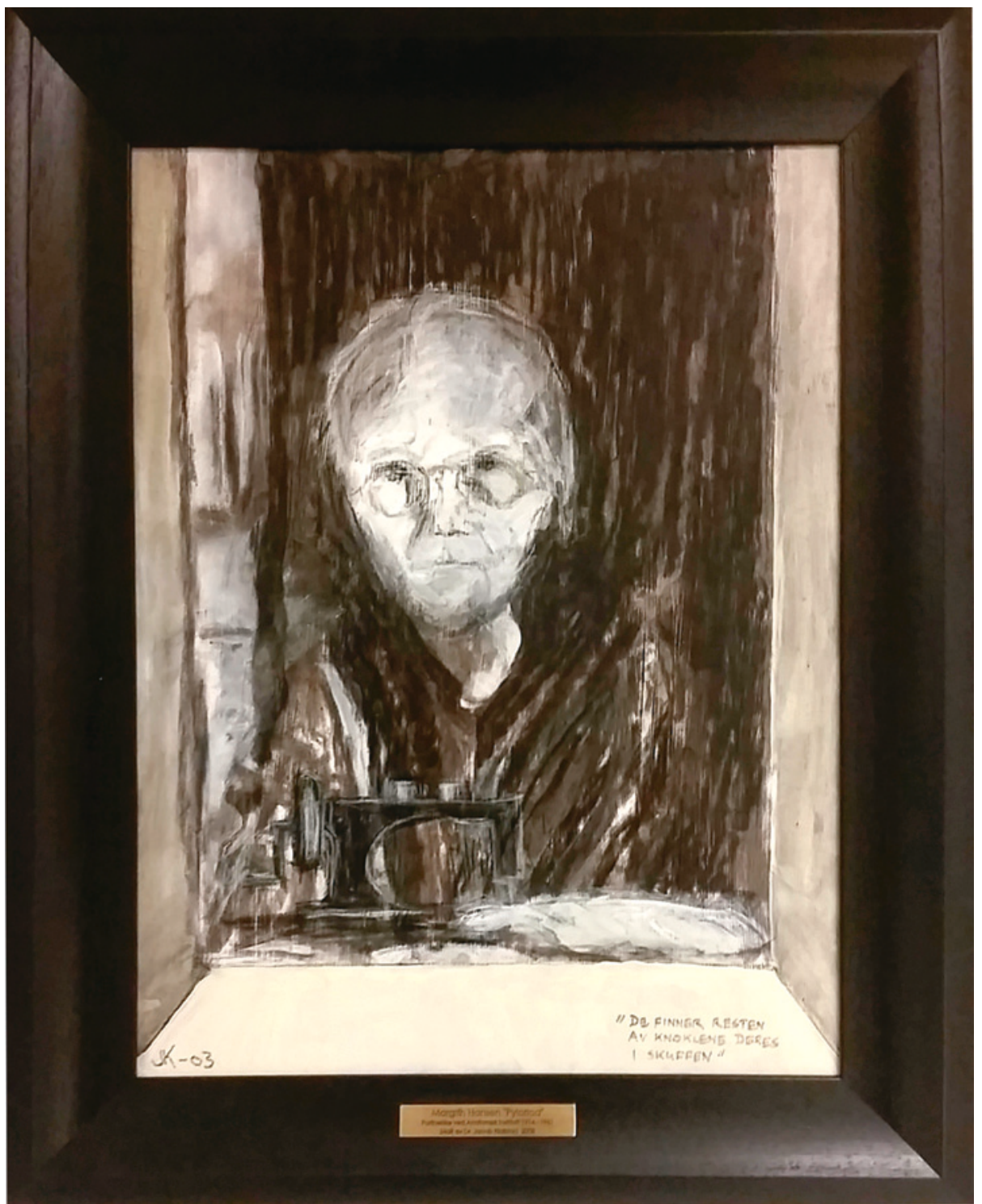

Figur 2 Akvarell av Pylorica malt av lege Jacob Klafstad i 2003. Bildet henger nå i Domus Medica, Universitetet i Oslo. Foto: Evelyn Voss

Hun satt der i luken i hele 47 år. Nå er vel alle portnersker erstattet med digitale inngangskort. Ansettelsesforholdene er uvisse, men det tekniske personalet med preparanter og kontorpersonell hadde på denne tiden en begynnerlønn på 1000 kroner årlig (Per Holck, personlig meddelelse). Preparantene hadde også sine spesielle kallenavn, jeg kan i alle fall huske en vi kalte «Ole Cranon».

Ved nåværende Avdeling for anatomi ved Universitetet i Oslo finnes ett eneste dokument om Margith Hanssen (Per Holck, personlig meddelelse). Hun fikk innvilget sykepermisjon på en måned i august 1945. Den ble innvilget av kollegiet og undertegnet av daværende rektor «D.A. Seip»

(1884-1963). rica deltok på disse samlingene. Ingen husker, kanskje hun måtte passe luken?

Personalet var samlet høytidelig to ganger om året: 17. mai før barnetoget og julaften formiddag. Da var alle i festklær, og sjefpreparant Alf Søderholm (1885-1981) kom i nyvasket frakk (Per O. Andersen, personlig meddelelse). Samme informant fortalte at Pylorica hadde en viss forbindelse med preparant Søderholm. Hun kunne ringe på en klokke hvis noe sto på, og da kom Søderholm nedover trappene «som ei kule». Søderholm var også ansatt på Anatomen i mange år $(1912-50)(9,10)$. Han fikk Kongens fortjenestmedalje i gull da han gikk av etter 38 års tjeneste i $1950(11,12)$. Pylorica hadde lengre ansettelse, men stillingen var ikke like prestisjefylt. I intervjuet med henne i 1961 står det at hun begynte i jobben i 1914, men i jubileumsboken ved Anatomisk institutts 150-årsjubileum står det at hun først begynte i 1917 (13).

I en bok om legestudenter i hovedstaden er hun kort omtalt: «der satt en gammel hvithåret dame med arbeidsforkle $\mathrm{i}$ svart sateng bak sin symaskin. Hun skuet strengt ut på de passerende gjennom en glassluke» (14). Svarte silkeforklær var arbeidsantrekket til mange kvinnelige hverdagsslitere: kontordamer, skrivemaskindamer, telefonistinner. De ble ikke enset stort, og det var nok få som fikk medaljer.

Inngangen til Anatomen var den gang en liten dør inn fra universitetshagen til østre fløy av Domus Media. Den førte inn til en liten forgang hvor Pyloricas luke var. Lenger inne var det en dør til et lite rom hvor hun arbeidet. Inngangen er som før, den brukes i dag av juridiske studenter som holder til i denne fløyen - nå med digitaliserte inngangskort. Pyloricas luke er murt igjen, men rommet hennes er som før, riktignok uten hennes symaskin.

Pylorica hadde også en annen oppgave: Hun hadde en samling menneskeknokler til utlån til medisinstudentene. Særskilt interesserte studenter kunne låne knokler og studere alskens tuberositae og foramina. Figur 2 viser en akvarell malt i 2003 (etter foto) av lege Jacob Klafstad (f. 1934). Teksten han har malt på bildet er «De finner resten av knoklene Deres i skuffen». Dette er en tenkt replikk, men Pylorica kunne godt ha uttalt den. De-formen var selvsagt, noe annet var ikke på tale, heller ikke mellom lærer og student.

Margith bodde i Vogts gate 55 helt til i 1970, da er hun registrert på Nordre gate 20 på Grünerløkka. Der bodde hun på det som den gang var Oslo indremisjons syke- 
hjem. Hun døde der 19.12. 1976, 90 år gammel. Dødsannonsen er bare undertegnet av hennes yngste søster, Guldveig, som hun hadde bodd sammen med hele tiden i Vogts gate (15). Hun ble kremert og gravlagt på Nordre gravlund. Graven er slettet (Gravferdsetaten i Oslo, personlig meddelelse).

Slik sluttet mine undersøkelser om Pylorica. Det jeg fikk vite var bare rammene om hennes liv, ingen ting om hennes personlige liv og tanker.

Margith Hanssen hadde, så vidt vi vet, ingen etterkommere, og det er snart 40 år siden hun døde. Selv om hun hadde et uvanlig langt tjenesteforhold ved universitetet, er det nesten ingen spor etter henne.

\section{Pylorica på veggen}

Da Aftenpostens fotograf $\mathrm{i}$ avskjedsintervjuet i 1961 prøvde å lokke frem et fødselsdagssmil i anledning 75-årsdagen, svarte hun: «Nei, jeg kan ikke smile, for jeg pleier ikke å gjøre det.» Hun så nok vanligvis litt streng ut for oss alle, men på vår omtalte kullfest smiler hun nydelig (fig 3 ).

Pylorica var sosial, det ser vi av bildene av henne på kullfesten, hvor hun smiler, drikker vin og snakker med studentene. Hun bodde sammen med sin - også ugifte søster i alle årene i Vogts gate. To frøkner sammen i en leilighet. Historien om hennes indre liv må gjettes, og eventuelt diktes, av hver enkelt av oss. Hun ble i Aftenpostens intervju spurt om hun nå var glad for å kunne gå derfra for siste gang. Hun svarte: «A, nei, det har vært trivelig her. Nesten for trivelig.»

Jacob Klafstads akvarell ble kjøpt av lege Jacob Havnen (f. 1934). Han har overlatt den til Anatomen ved Institutt for medisinske basalfag i Domus Medica på Gaustad i Oslo. Der har den nå fått veggplass, ramme og en plakett med opplysninger. Bildet befinner seg i korridoren i kontorseksjonen, ikke blant koryfeene i det nye Auditorium 13. Pylorica ville nok ha trivdes best i denne delen selv også.

Jeg takker Per O. Andersen, Guri Bramness, Jacob Havnen, Erlend Hem, Per Holck, Jacob Klafstad, Holger Ursin, Evelyn Voss og Anne Vaalund for nyttig informasjon.

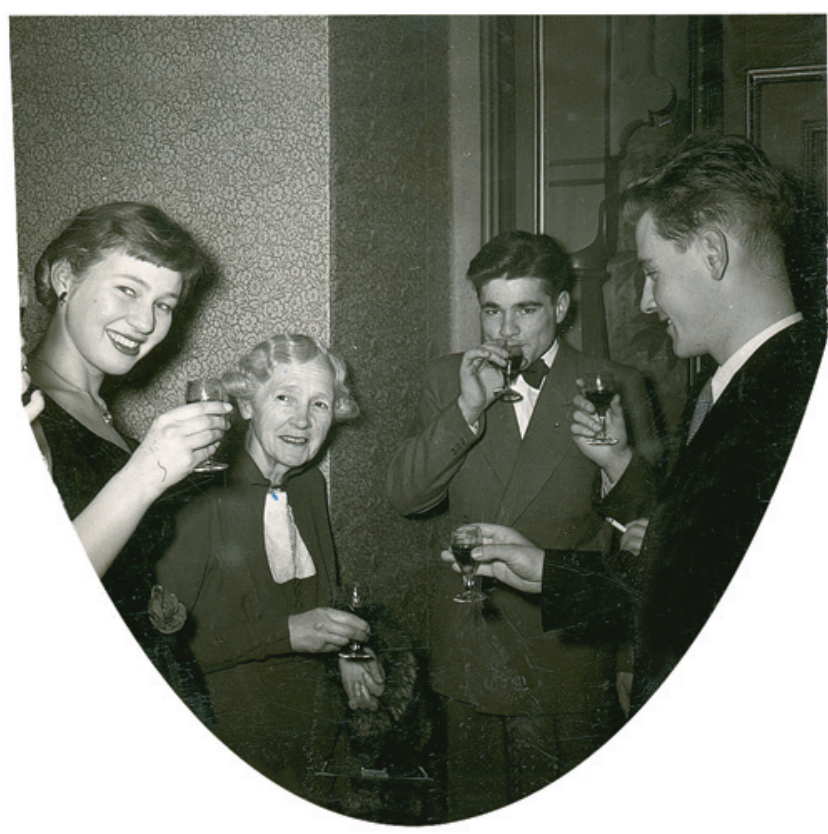

Figur 3 Fra en kullfest høsten 1954. Fra venstre ses medisinstudentene Bjørg Thorsen (nå Vinje), Pylorica, Jens Aamold og Kjell Hornslien. Foto: Privat

\section{Rannveig Nordhagen}

roge.nordhagen@gmail.com

Rannveig Nordhagen (f. 1933) er dr.med., spesialist i immunologi og transfusjonsmedisin og tidligere overlege og seniorforsker ved Nasjonalt folkehelseinstitutt.

Ingen oppgitte interessekonflikter.

\section{Litteratur}

1. Barbery M. L'élégance du hérisson. Paris: Gallimard, 2006

2. Presseklipp 1961: 47 år ved døren til «Anatomen». Museum for universitets- og vitenskapshistorie, Universitetet i Oslo, 25.10.2012. Gjengitt fra Aftenposten aften 11.11.1961: 5. www.muv.uio.no/ uios-historie/spesialtemaer/presseklipp/skjultfra-sokekomp-likt-ulikt/47-aar-bvj-300409.htm (29.11.2014).

3. Akershus fylke, Eidsvoll i Eidsvoll, Ministerialbok nr. 2 (1882-1895), Fødte og døpte 1886, side 56. www.arkivverket.no/URN: NBN: no-a1450kb20060512010552.jpg (29.11.2014).

4. Folketelling 1900 for 0237 Eidsvoll herred. http://digitalarkivet.arkivverket.no/nn-no/ft/ person/pf01037041004084 (29.11.2014).

5. Folketelling 1910 for 0301 Kristiania kjøpstad http://digitalarkivet.arkivverket.no/nn-no/ft/ person/pf01036392164005 [29.11.2014]

6. Piker i hvitt. Alle Kvinners Blad 26.4.1952.
7. Waal H. Nic Waal: det urolige hjerte. Oslo: Pax, 1991: 41. www.nb.no/nbsok/nb/ 6b20834bad816e52e8b4bbb7558c9c3c?index=9\#41 (29.11.2014)

8. Fra Anatomen. Esculap 1940: 180-1.

9. Hopstock H. Det anatomiske institut: 23. januar 1815-23. januar 1915. Kristiania: Aschehoug. 1915: 139 www nb no/nbsok/nb/ e45842a52d50685dd20042ce3887ca1a?index=7\#15 3 (25.1.2015)

10. Aftenposten 4.4.1916: 4

11. Hos Kongen. VG 21.12.1950: 2

12. Søderholm, Alf 1.7.1950. Tildelinger av ordener og medaljer. Det norske kongehus. www.kongehuset.no/tildelin-

ger.html?tid $=113160 \&$ sek $=27337 \& q=\&$ type $=27125$ \&aarstall=1950 (1.2.2015)

13. Getz B. Anatomisk institutt, Universitetet i Oslo: 1815-1965. Oslo: Universitetsforlaget, 1965: 82

14. Larsen $\emptyset$. Legestudent i hovedstaden: medisin på stadig nye måter. Oslo: Gyldendal Akademisk 2002: 21.

15. Dødsfall. Aftenposten 21.12.1976: 15

Mottatt 7.2. 2015, første revisjon innsendt 27.4. 2015, godkjent 11.5. 2015. Redaktør: Sigurd Høye. 